\title{
A review of medical airlifts by a search and rescue squadron on the east coast of England over 18 years

\author{
M. J. WILLIAMS
}

Registrar in Accident \& Emergency Medicine, Hull Royal Infirmary, Anlaby Road, Hull.

\section{SUMMARY}

This paper reviews the medical workload of a Royal Air Force Search and Rescue $\stackrel{\stackrel{\sim}{\circ}}{\circ}$ squadron on the East Coast of England over a period of 18 years and their $ᄋ$ association with the principal receiving hospitals in that area. It illustrates the effects of improvements in road networks on the workload of the squadron and contrasts the use of military helicopters with established U.K. civilian helicopter $\bar{\oplus}$ schemes.

\section{INTRODUCTION}

The Search and Rescue Wing (SAR) of the Royal Air Force operates the yellow $\stackrel{\circ}{\Rightarrow}$ helicopters of Nos. 22 and 202 squadrons, from nine locations around the U.K. coast. The ' $E$ ' Flight 202 squadron based at Leconfield some 12 miles north of Hull, operates two Sea King helicopters, the larger of the two types of helicopter operated by the SAR wing, the other being the Wessex (Fig. 1). The Sea King has an operational radius of $\mathbf{2 8 0}$ nautical miles. Although established primarily for the rescue of military aviators and personnel, over $90 \%$ of call outs are to civilian incidents.

\section{AIM}

The aim of the study was to review the association of the Royal Air Force SAR squadron at Leconfield with the principal receiving hospitals in the area and to

Correspondence: Michael J. Williams, Registrar in Accident \& Emergency Medicine, Hull Royal Infirmary Anlaby Road, Hull HU3 2JZ, U.K. 


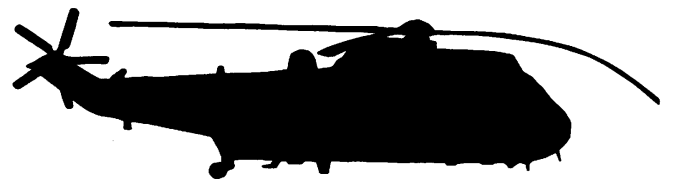

WESTLAND SEA KTNG (1969) (U.S.A.U.K.)

Length $17 \mathrm{~m}$

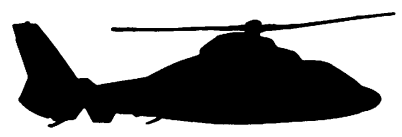

SA 365 DAUPHIN 2, 1975 (France) Length $11.20 \mathrm{~m}$

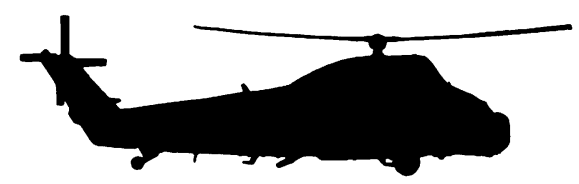

WESTLAND WBSSEX, 1957 (United Kingdom) Length $11.92 \mathrm{~m}$

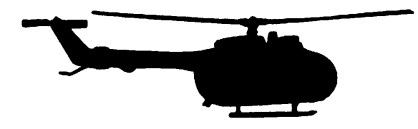

MESSERSCHMITT BO 105, 1967 (Germany) Length $8.50 \mathrm{~m}$

Fig. 1 Comparative size of aircraft used in aeromedical evacuation in the UK.

illustrate the significance of changes in road transportation in relation to the medical evacuation workload of the squadron.

\section{MATERIALS AND METHODS}

Inspection and analysis of the duty flight log of the squadron from 1972-1989.

\section{Background}

The area on the East coast of England comprising of Humberside (formerly East Yorkshire \& North Lincolnshire), North Yorkshire and parts of Lincolnshire are served by the RAF SAR squadron based at Leconfield (Fig. 2). The main receiving hospitals are at Hull, Scarborough and Grimsby. The subregional neurosurgical and cardiothoracic units are at Hull. The crew are normally scrambled to a rescue incident by one of the RAF Coastguard Rescue Coordination Centres (RCC) at Edinburgh or Plymouth, who may have received the request from any number of agencies such as the Coastguard, Police, or directly from the general public.

The majority of calls are from maritime vessels, occasionally a casualty will be recovered from one of the numerous oil and gas platforms in the North Sea. Unless a casualty on a rig needs to be seen by a doctor at the scene they will routinely be airlifted by company aircraft. Medical staff who may find themselves flying with the helicopter crew undergo a training day when they are familiarized with the helicopter and the winching manoeuvres. They are then winched out at sea on to the deck of a suitable vessel to become aware of the problems they may encounter on a 'real' scramble. 


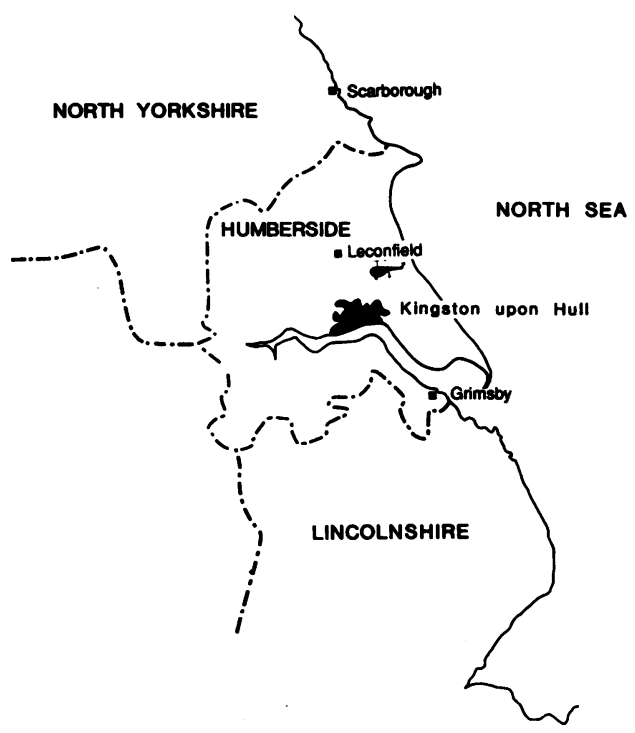

Fig. 2 Relation of RAF Leconfield to principal receiving hospitals.

\section{FINDINGS}

The majority of medical airlifts were to the three hospitals shown on the ma (Fig. 2), most to Hull (Fig. 3). Interhospital transfers were mostly from hospitals on the South bank of the Humber estuary and usually involving the transfer of serious head injuries to the neurosurgical unit at Hull. Some transfers outside the area, particularly from Scarborough, were for cases of barotrauma (the bends), requiring transfer at low altitudes to the North Sea diving centre at Great Yarmouth for decompression. On a few occasions transfer of medical cases to specialized units e.g. for liver and heart transplantations has taken place, but these were exceptional. They account for most of the inter hospital transfer cases from Hull (Fig. 4). Medical assistance was often for injured patients. Most cases were relatively minor but evacuation was indicated due to the vessel being far from port. Medical emergencies were common conditions such as cerebrovascular problems, fits and diabetic comas.

Prior to the opening of the world's longest single span suspension bridge over the Humber estuary in 1981, there were a significant number of inter hospital transfers from the south bank of the Humber estuary to Hull for treatment. Most of these were for head and spinal injury cases. The road journey prior to the bridge being built was about 60 miles and could take 1.5-2h. There was a ferry service across the Humber, but this was dependent on climatic and tidal conditions and did not operate at night. After the bridge was opened the road journey time was reduced to half an hour and there has been a marked fall in inter hospital transfers (Fig. 4). 


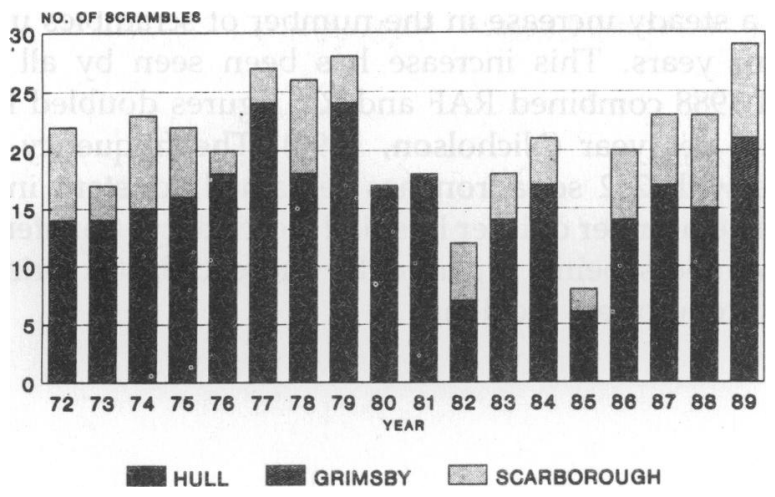

Fig. 3202 Squadron analysis by hospital of total medical flights.

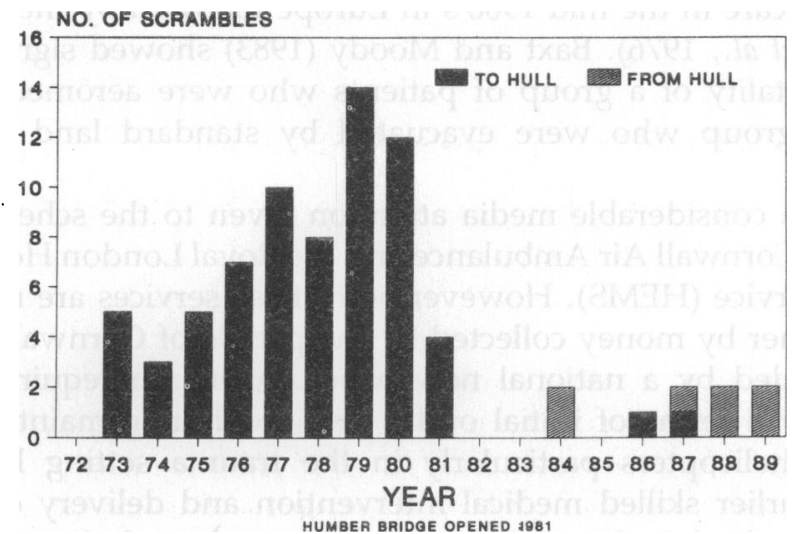

Fig. 4202 Squadron Interhospital flights to and from hull.

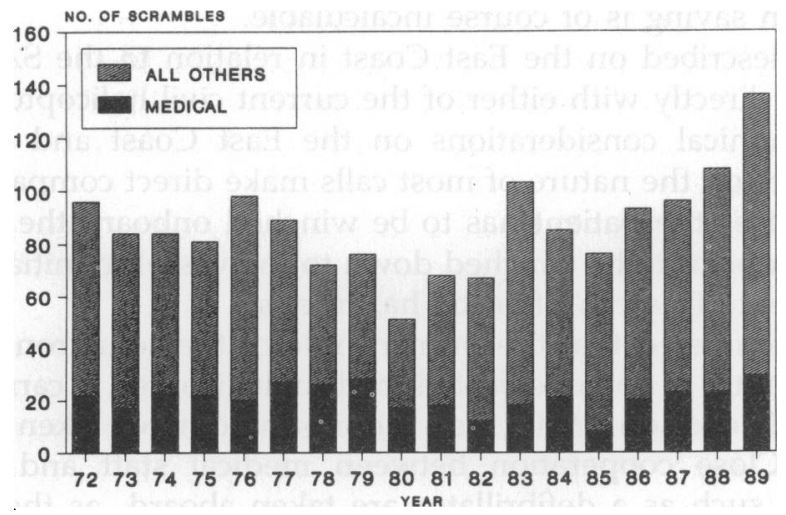

Fig. 5202 Squadron airlift trends - medical vs. all other. 
There has been a steady increase in the number of scrambles undertaken by the $\mathrm{T}$ squadron in recent years. This increase has been seen by all SAR squadrons. $\frac{\mathbb{D}}{\mathrm{O}}$ Between 1984 and 1988 combined RAF and RN figures doubled from some 900 to over 1800 call outs per year (Nicholson, 1990). The frequency of scrambles for $\stackrel{\odot}{\circ}$ medical assistance with 202 squadron has remained constant in the time period $\Rightarrow$ analysed (Fig. 5). The number of inter hospital (secondary) transfers has diminished $\stackrel{\text { of }}{\rightarrow}$ markedly, their numbers being replaced by more calls for primary transfers of patients from the scene of an accident.

\section{DISCUSSION}

The use of the helicopter in the immediate care environment has been widespread in the USA and parts of Europe since the late 1960's. Helicopters were first dedicated totally to patient care in the mid 1960's in Europe followed by the United States in iv 1972 (Cleveland et al., 1976). Baxt and Moody (1983) showed significant reduction in predicted mortality of a group of patients who were aeromedically evacuated compared to a group who were evacuated by standard land prehospital care $\stackrel{?}{-}$ services.

There has been considerable media attention given to the schemes currently in operation by the Cornwall Air Ambulance and the Royal London Hospitals' Helicop- $\vec{\bullet}$ ter Emergency service (HEMS). However both these services are run by charitable $\stackrel{\oplus}{-}$ support, the former by money collected by the people of Cornwall and the HEM helicopter is funded by a national newspaper. Although requiring considerabe financial support in terms of initial outlay and continuing maintenance, the cost effectiveness of helicopters particularly in the trauma setting has been clearly demonstrated. Earlier skilled medical intervention and delivery of the patient to an appropriate medical facility reduces mortality and morbidity and considerably reduces time spent on intensive care units with substantial cost savings. The return of a trauma patient back to employment and taxable revenue more than repays the costs of treatment, including transfer by helicopter (Postlethwaite, 1987). The human saving is of course incalculable.

The situation described on the East Coast in relation to the SAR squadron can not be compared directly with either of the current civil helicopter schemes in the 8 U.K. The geographical considerations on the East Coast and in particular the maritime influence on the nature of most calls make direct comparison difficult. In 9 the majority of cases the patient has to be winched onboard the helicopter, often $\frac{7}{0}$ necessitating the doctor to be winched down to the vessel to initiate treatment and stabilize the patient. This can often be hazardous.

It must be remembered that the primary role of the squadron is to search and $\tilde{O}$ rescue. The helicopter is not a dedicated medical helicopter, it carries basic medical $\underset{\omega}{N}$ equipment only (Nicholson, 1990). Any monitoring devices taken have to be taken $₹$ by the doctor. Close cooperation between medical staff and aircrew is vital $\stackrel{\circ}{\leftarrow}$ when equipment such as a defibrillator are taken aboard, as their use can cause $\stackrel{\oplus}{\oplus}$ considerable problems with the aircrafts electronic equipment (Postlethwaite, 1987). 
A pulse oximeter (Ohmeda Biox 3740) has been found to be a valuable tool for patient monitoring, this has also been the experience of others (Mulrooney, 1990). Currently in Hull, the helicopter picks up the doctor en route to the incident from a designated landing ground (a cricket pitch) near the hospital. Both Scarborough and Grimsby have a helipad on the hospital site, which is preferrable. However there is still the need to transfer the patient to a waiting ambulance to convey him to the doors of the Accident department, which is a less than optimal situation. The Sea King and Wessex helicopters used by the RAF are considerably larger than the Messerscmitt BO 105 used by the Cornwall Air Ambulance or the London HEMS Dauphin helicopter (Fig. 1). However as has been demonstrated in incidents such as the M1 air crash, the Sea King can be landed at the roadside with adequate ground organization.

The Sea King is not a dedicated medical helicopter and as such can not offer the facilities of a comprehensive mobile intensive care unit as other schemes can (Patrick \& Lawler, 1989). Medical staff attending primary transfers must have a broad range of experience in emergency medicine, currently all requests for medical assistance are met by a doctor of Registrar status or above. In the same way it is vital that adequately trained staff capable of dealing with any problem that may arise accompany the inter hospital transfers. However because there are only about 25 medical airlift cases a year, the experienced gained by any one doctor is limited.

Arguments for and against the use of helicopters in the U.K. continue (Nicholson, 1988; Bristow \& Evans, 1990; deMello \& Thompson, 1990; Ramage et al., 1990). It has been suggested that perhaps the signs of change are on the horizon (Laing, 1989), with the success of the Cornwall Air Ambulance and the evolution of the HEMS helicopter.

It must not be forgotten that there already exists a network of helicopters strategically placed around the U.K. coastline. They currently provide $24 \mathrm{~h}$ cover with a $15 \mathrm{~min}$ readiness time during daylight hours and $45 \mathrm{~min}$ after darkness. No individual organization is billed for the services of a helicopter in a rescue situation, but the cost of this service is high and so it should be used appropriately. A charge is levied for interhospital transfers, this is billed to the health authority where the patient resides, this relieves the burden of payment on the authority where the helicopter is based. As a counter argument to the high cost, helicopter crews need regular training sorties, so that some call-outs will satisfy this demand.

It is essential that the close liaison, training and cooperation that exists between such SAR units and civilian hospitals be further developed and encouraged for optimum patient care with existing resources.

\section{ACKNOWLEDGMENTS}

I am grateful to Flight Lieutenant M. Counter, Officer commanding 'E' Flight 202 Squadron, for permission to use the data from the flight logs. I would also like to thank all the aircrew whose professionalism and bravery have ensured the safety of attending medical personnel over the years. 
I would also like to thank $\mathrm{Mr} \mathrm{J}$. Crawley for his assistance in reproducing the graphics and the Medical Illustrations Department, Hull Royal Infirmary, for producing the art work.

\section{REFERENCES}

Baxt W. G., Moody P. (1983) The impact of a Rotorcraft Aeromedical Emergency Care Service on trauma mortality. JAMA 249, 3047-51.

Bristow A. \& Evans I. (1990) A dedicated helicopter based ITU has all the advantages. British Journal of ${ }^{\infty}$ Hospital Medicine 44, 91.

Cleveland H. C., Bigelow D. B., Dracon D., et al (1976) A civilian air emergency service: A report of its development, technical aspects and experience. Journal of Trauma 16, 452-63.

Mulrooney P. (1990) Monitoring during aeromedical transfer. Anaesthesia 45, 256.

de Mello W. F. \& Thompson M. (1990) The disadvantages of helicopter transfer. British Journal of 3 Hospital Medicine 43, 328.

Nicholson P. J. (1988) The Helicopter in the Immediate Care Environment. Journal of the British Association of Immediate Care 11(3), 554-7.

Nicholson P. J. (1990) The Royal Air Force and the Rescue of Civilian Casualties. In: BASICS Monographs 음 on Immediate Care No. 4, pp. 3-12.

Postlethwaite A. (1987) Cost of Living. Flight International June 20, 60-62.

Puttick N. P. \& Lawler P. G. P. (1989) Pulse oximetry in mountain rescue and helicopter evacuation. Anaesthesia 44, 867.

Ramage C., Kee S. \& Bristow A. (1990) Interhospital transfer of the critically ill patient by helicopter. British Journal of Hospital Medicine 43, 147-8.

Laing G. S. (ed) (1989) Royal Society of Medicine: The AEE Letter. 2(3). 